CPB Memorandum

CPB Netherlands Bureau for Economic Policy Analysis

$\begin{array}{ll}\text { Sector } & : \text { Physical aspects } \\ \text { Unit/Project } & : \text { Spatial Economics } \\ \text { Author(s) } & : \text { C.J.J. Eijgenraam } \\ \text { Number } & : 213 \\ \text { Date } & : 7 \text { januari } 2009\end{array}$

\title{
From optimal to practical safety standards for dike-ring areas
}

\begin{abstract}
$^{1}$
After the flood disaster in 1953 in the southwestern part of the Netherlands, Van Dantzig tried to solve the economic decision problem concerning the optimal height of dikes. His solution has a fixed probability of flooding after each investment (Econometrica, 1956). However, when there is economic growth, not the probability of flooding but the expected yearly loss by flooding is the key variable in the real optimal safety strategy. Under some conditions, it is optimal to keep this expected loss within a constant interval. Therefore, when the potential damage increases by economic growth, the flooding probability has to decline in the course of time in order to keep the expected loss between the fixed boundaries. The purpose of the paper is to show the implications of the optimal solution in case there are differences between costs and benefits among dike-ring areas. Further, the paper focuses on the translation of the theoretical results into new legal standards that can work well in practice.
\end{abstract}

Key words:

Cost benefit analysis, optimal height of dikes, optimal safety standards.

\footnotetext{
${ }^{1}$ The author thanks J. Gauderis, J. Kind and W. Oosterberg (all RIZA), R. Okker (CPB) and a referee for their comments on earlier versions. The responsibility for the content of the paper remains with the author. The paper was presented on June 26, 2006 at the conference "Innovations in coping with water and climate risks", organized by the International Water Association (IWA) in Amsterdam. It was published in 2007 in the IWA journal "Water Science and Technology", volume 56, issue 4 , pp 113-124.
} 


\section{The Economic Decision Problem about the Optimal Safety of Dike-ring Areas}

\section{$1.1 \quad$ Introduction}

11 million people in the Netherlands or two/third of the population live in dike-ring areas that are vulnerable for serious flooding. ${ }^{2}$ These dike rings are situated in the north and western parts of the country and along the big rivers Rhine and Meuse. Obviously, an important question is: What is the optimal strategy for protecting a dike-ring area against flooding? or in other words: What is the optimal height of a dike? The theoretical solution and his implications are described in the first part of the paper.

In the Netherlands, the Act on the Water Defences gives for different types of dike rings a standard for the maximum exceedance probability of the design-water level a dike section must sustain. ${ }^{3}$ These exceedance probabilities range from $1 / 250$ per year for small levees in the valley of the Meuse, via 1/1250 per year for dike rings along the upper part of the Rhine and the Meuse, till 1/10000 per year for the most important dike rings along the coast.

In November 2005 the Ministry of Water Management started a broad discussion what changes have to be made in the law and in the height of the safety standards. Therefore the last part of the paper will be devoted to the design of a strategy that will work well in practice and has been based on the theoretical results.

\subsection{Solution of the safety problem}

One can always get more safety, albeit at increasing costs. However, in most situations absolute safety can never be reached. That is especially the case along the sea. Irrespective how high the dike is, there is always a residual chance on flooding and damage. We can and have to make choices how far we go with our water defences. So the central question is:

At which size of investment, e.g. in heightening dikes, are the social costs of an additional investment bigger than the social benefits of the extra decrease of the expected loss?

At that point: stop investing.

\footnotetext{
${ }^{2} \mathrm{~A}$ dike ring is an uninterrupted ring of water defences, like dikes or dunes, and high grounds which even under the most unlikely circumstances will not be flooded. The area that is protected by a dike ring, is sometimes also referred to as 'polder'. ${ }^{3}$ In the discussion about safety standards in the Netherlands the word 'exceedance probability' is used in two related, but different meanings. The first is the statistical meaning of the cumulative probability of the occurrence of an event bigger than a certain value, for instance a water level that exceeds the design-water level of a dike.

The second meaning of exceedance is a civil engineering one. It refers to a flooding caused by overtopping. When the dike has been well constructed, flooding as a result of other failure mechanisms (e.g. piping) should have a probability which is an order of magnitude smaller than the probability of overtopping. The present legal standards in the Netherlands have been based on this premise. So, we use the expression 'exceedance probability' in both meanings.
} 
This is an economic question with a rational solution, but in the end political decisions have to be taken. Politicians have a task in specifying what is relevant for the social costs and social benefits. In the end they have the task to weigh the unweightable, like the value of human lives, the value of the natural environment or the extent of risk aversion. I shall not address these matters in this paper and I will simply suppose that all costs and benefits can be expressed in the form of amounts of money.

The economic problem of optimal safety is basically one of cost minimisation. Generally speaking, people want to maximise their utility in spending their income. The water problem restricts income in two ways: by having losses by flooding and by spending money on actions to prevent flooding. ${ }^{4}$ So, in this case maximising utility is the same as minimising the total costs involved with water defences plus the losses by flooding in the course of time.

The difficulty in solving the problem mathematically is that none of the factors influencing the solution is constant in time. First there is the deterioration of the water system. Reasons can be climate change and subsidence of land. Therefore, as long as we take no action, the probability of flooding rises. Second there is the growth of population and wealth in the dike-ring area. The result is that the potential loss by flooding increases. For both reasons this means that the expected loss by flooding per year increases. In simple cases expected loss by flooding is the probability of flooding per year times the loss by flooding. ${ }^{5}$

These continuing changes imply that in the course of time additional actions will be necessary. Moreover, the size and the timing of each investment influence at least the timing of later decisions.

A further complication is that there are fixed investment costs. These are costs which are not dependent on the size of the action (in this paper heightening of dikes), e.g. preparing the plan or the costs of bringing the equipment to the construction site. These fixed costs lead to the conclusion that we should choose the size of the actions not too small. Fixed costs also imply that it is not efficient to invest continuously on the same spot. So, there are obviously two questions to answer: When? and: How much to invest?

Figure 1.1 shows the essentials of the solution. On the vertical axis stands the expected loss. A high expected loss (meaning a low safety level) has been pictured at the top of the graph and a low expected loss at the bottom of the graph. Starting from the left side of the graph the expected damage increases till that amount reaches a ceiling: an amount of expected damage beyond that ceiling we consider as unacceptable. On that moment we do an investment which brings the safety level to a certain high level, lowering the amount of expected damage. But it is

\footnotetext{
${ }^{4}$ In answering this question I restrict the possible actions to structural safety measures (prevention) given spatial situations and developments. An important reason is that a lot of the material damage can not be diminished by evacuation. Further I speak only about heightening of dikes, but several other types of action are also possible, especially along rivers.

${ }^{5}$ More complicated cases can also be handled within the same framework, see Eijgenraam, 2006, section 3.7. 
not worthwhile to diminish this amount further. From that point on, the amount of expected damage begins to rise again till it hits the ceiling again and then the whole process starts again from the beginning, but with a higher level of the dike. It is clear that the formulas for the upper and lower bounds of the interval are the answers to the questions when and how much to invest (see for mathematical derivation Eijgenraam (2005) or (2006)).

\section{Figure 1.1 Basic strategy for heightening a dike ring (= diminishing residual damage)}

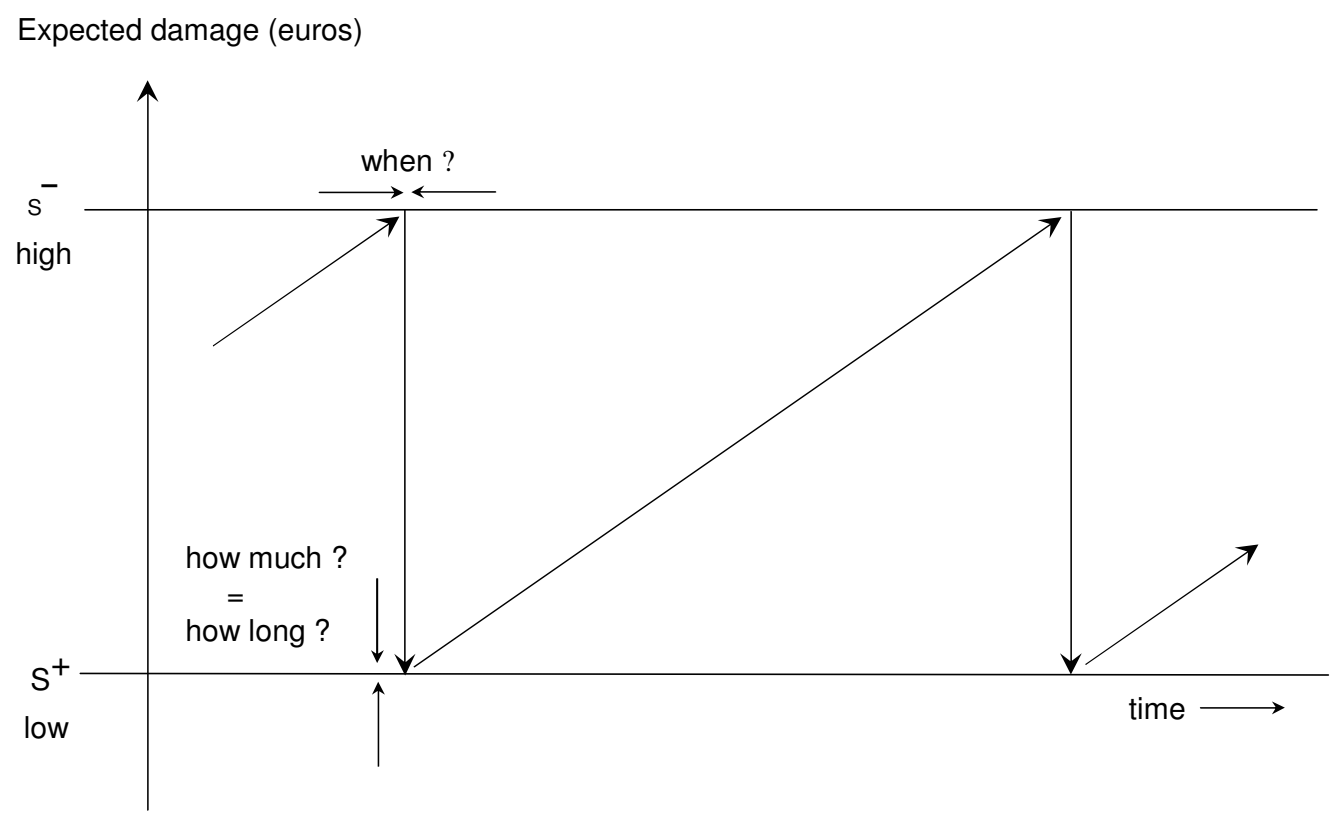

The real difference compared to an earlier attempt to find the solution of this problem (Van Dantzig, 1956) is that the correct interval is in terms of expected loss. This is already clear from the central question that we need to find the point where the diminishing benefits of the action or, in other words, the diminishing of expected losses, become equal to the rising costs of investment. Earlier, people thought that the interval was in terms of probabilities of flooding, meaning that after each investment the probability of flooding should be the same. In doing so, only the deterioration of the water system will be repaired, but the increase in the loss by flooding (inhabitants, wealth) would not be taken into account. At present the Act on the Water Defences in the Netherlands has still been based on this idea. However, according to the real optimal solution not the probabilities of flooding but the expected loss must be kept between more or less constant boundaries. This means that the probabilities of flooding have to decline at almost the same rate as the loss by flooding is increasing. Otherwise expected loss can not be almost constant in time. 


\subsection{An example of an actual solution}

Figure 1.2 shows the outcome of the calculation for the dike ring number 43 Betuwe (CPB, 2005). The lines at the top (Pmin) and the bottom of the graph (Pplus) show the two bounds for the probability of flooding. These bounds are becoming smaller as the consequence of economic growth in this area. The solid, uninterrupted line is the optimal development of the actual probability of flooding $(\mathrm{P})$. The horizontal line in the middle is the actual legal safety standard (Pwet). For this dike ring the legal maximum (exceedance) probability of flooding is $1 / 1250$ per year.

\section{Figure 1.2 Probabilities of flooding for dike ring 43 Betuwe}

Probability

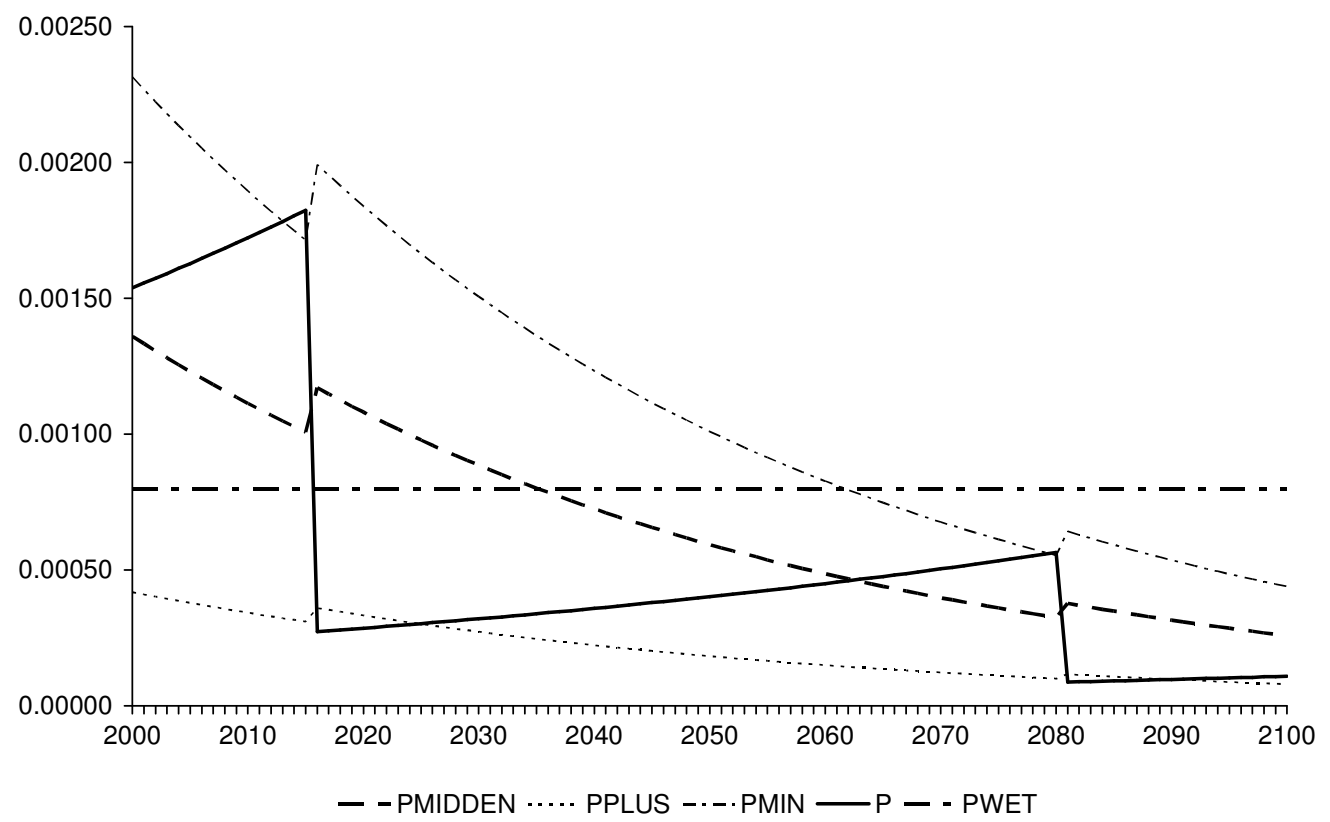

In 2001 new insights implied that the actual probability was twice what is allowed by the law. The project 'Room for the Rivers' aims at bringing the actual safety for this and other dike rings along the Rhine back to the legal standards by 2015 . Coincidently that is almost exactly the calculated optimal timing, as can be seen in Figure 1.2. But that was only the case for this particular dike ring. In most other dike-ring areas there is nowadays a real backlog compared with the upper bound of the optimal probability interval (see e.g. Eijgenraam (2005)). 


\section{Implications of the optimal solution}

\subsection{The middle probability of flooding}

To get a good idea of the main implications of the solution it is not necessary to look at all the formulas of the interval, because both bounds move in line which each other. It is sufficient to look more closely at the centre of the interval of expected loss. Another advantage in doing so is that the centre has a clear and simple relation with the question we started with, namely: what is the best balance between expected loss and investment costs? Essentially, the answer is that we should keep the value of the expected loss per year in the neighbourhood of the yearly costs of some well defined standard investment action (see for details the appendix). When we go that far with our defence actions, we come in a situation we want to be: right in the hart of the optimal interval of expected loss.

The formula for the centre of the interval of expected loss is (see the appendix):

Mean expected loss $\approx$ yearly costs of a standard investment

To find the middle of the probability interval we apply the definition of expected loss (probability times effect) to the outcome of (2.1):

$\begin{aligned} \text { Middle probability of flooding } t_{t} & =\frac{\text { mean expected loss }}{\text { loss by flooding } t_{t}} \\ & =\frac{\text { yearly costs of a standard investment }}{\text { loss by flooding }{ }_{\mathrm{t}}}\end{aligned}$

Or in words:

The middle optimal yearly probability of flooding in a year is the yearly costs of a certain standard investment divided by the loss by flooding in that year.

This formulation is all we need to know to understand the most important implications of the solution of the cost-benefit analyses.

\section{$2.2 \quad$ Future developments}

\section{Optimal probabilities of flooding become smaller}

In general, during the period between two investments the average costs of investment stay the same. But normally, the loss of flooding in the denominator of (2) increases as the consequence 
of the growth of the number of inhabitants and the economy. Therefore, after each investment the optimal probabilities of flooding become smaller in the course of time, see Figure 1.2.

\section{Optimal probabilities of flooding rise a bit after each investment}

Normally, the costs of actions become higher as the height of the dike increases. One of the reasons is that during each heightening the dike also has to become broader. As the numerator in (2) becomes bigger, the optimal probability of flooding becomes higher. This can also be seen in Figure 1.2. After each investment the bounds make a little jump upwards.

\section{Sustainability (e.g. under climate change) ${ }^{6}$}

As long as the rate of economic growth is bigger than the rate of growth of the investment costs, the optimal probabilities of flooding will decrease. Then the total costs of flooding and investment are a declining fraction of regional income. This implies that the whole safety system is sustainable. When the rate of growth of costs becomes bigger than the rate of economic growth, all conclusions turn into their opposites.

\subsection{Differences between dike-ring areas}

\section{Much damage (many inhabitants) implies higher optimal safety than little damage}

Suppose we compare the optimal probabilities of flooding between two dike rings with the same standard costs of investment. If the damages by flooding in the two dike rings differ, the dike ring with the biggest damage has the lowest optimal probability of flooding (highest optimal safety level).

When the amount of damage per head of the population is the same, it means that a dike ring with two times the number of people as in another dike ring has an optimal probability of flooding that is only half the optimal probability of flooding of the dike ring with the least number of inhabitants. So, societal risk is taken into account, albeit only in a roughly direct proportional way. Of course, this does not rule out the possibility that in a more accurate calculation the total amount of damage by flooding turns out to be more than proportional dependent on the number of people. Reasons can be that the material damage per head increases because there are in cities relatively more jobs per head of the population than in rural areas. Another reason can be that the cost of evacuation increases more than proportional with the number of people.

Dividing a dike ring into compartments and thereby restricting the damage of a flooding to one compartment can sometimes help to lower the total costs of prevention and flooding. However, because the 'bathtub' becomes smaller, making compartments can increase the speed

\footnotetext{
${ }^{6}$ See Eijgenraam (2006) section 3.5 for an extensive treatment of stability and sustainability in case of increasing costs.
} 
of the rise in water level and maybe thereby increase the actual number of victims. So the utility of making compartments depends clearly on the particular situation at hand.

\section{High costs (long dike) imply a lower optimal safety than low costs}

If the costs of investment differ between dike rings, the dike ring with the biggest costs has the highest optimal probability of flooding. Other things equal, it means that a dike ring with a dike that is two times longer than the dike of another dike ring, has an optimal probability of flooding which is twice the optimal probability of flooding in the dike ring with the short dike.

\section{Differences between dike rings mean different optimal probabilities of flooding}

Combining the implications of different costs and benefits gives no clear indication whether the optimal probability of flooding in a small dike ring would be lower or higher than in a big dike ring. If costs and benefits would be perfectly correlated between dike-ring areas, their optimal probabilities of flooding are exactly the same. This can easily be seen with the help of formula (2). Multiplying the costs in the numerator and the potential damage in the numerator by the same factor, for instance 2, does not change the optimal probability of flooding at all.

But in practice any correlation between standard costs and damage turns out to be almost absent. So in practice very different optimal probabilities of flooding for dike-ring areas result out of actual calculations (see Eijgenraam (2005) or (2006) or CPB (2005)).

\subsection{Efficiency versus equality}

The result in the previous section shows that the fact that the solution found is the most efficient one, will not automatically mean that it is the most wanted solution from the point of view of equality, in the sense that everyone has the same probability of flooding. However, from some point of view the efficient solution is also an equal one.

\section{The same amount of money for everyone?}

Suppose we give in a country everyone who lives in a dike-ring area, the same amount of money to spend on his own dike ring. Then dike rings with many people will get proportionally more money than dike rings with a small number of people. Further, the amount of money available per kilometre dike is dependent on the number of kilometres dike. So, the outcome of this equal distribution of money will be that the probabilities of flooding are directly proportional to the costs of investment (length of the dike) and inversely proportional to the number of people (amount of damage). These properties are the same as those of the efficient solution according to equation (2), as we have seen in the previous section. So, the optimal efficient solution gives roughly the same ranking of probabilities of flooding as giving everyone the same amount of money to spend on the dikes in his own dike ring (equality of input). 


\section{Minimum safety level}

However, besides the differentiated outcomes of the efficient solution, people can feel a need for a standard based on the equality of results. This means the guarantee of a certain minimum safety level for every dike-ring area of a certain minimal size (e.g. with more than one thousand inhabitants) in which serious flooding can occur. By definition, the value for this minimum safety level can not be based on cost-benefit analysis. It is a purely political decision. A possible candidate in the Netherlands is the lowest safety level mentioned in the present law; that is a maximum exceedance probability of $1 / 1250$ per year.

\section{Insurance}

It is important to realise what the word 'optimal' means when we speak about an optimal economic safety level. It simply means that it is cheaper for the organisation which pays the costs of investment, to bear the costs caused by the remaining floods than to invest more in safety. When the society (government or water board) chooses to implement the cheapest safety solution for each dike ring separately, it may be considered logical that the same organisation also pays for the remaining damage. An individual has no influence at all on the probability of the accident: not on the standard nor on the implementation. Responsibility for paying the remaining damage gives the organisation responsible for the water defences the correct stimulus to invest the right amount of money. Further it is an other way of restoring the balance between citizens in dike rings where totally different safety levels are implemented. And it is certainly cheaper than raising the minimum safety level everywhere.

In fact, this is of course not a new task for the government. The national government has always paid a considerable part of the losses by flooding, because it is the only organisation to fall back on in circumstances like an extensive flooding. The amount of losses in case of a serious flood will be very high (tens of billions of euros or even more). On the other hand the chance of occurring is very small (less than one in more than thousand or even ten thousand years when the standards are correct and correctly implemented). This leads to relatively small risk premiums per year and extremely long contract periods. It is not at all clear how a private insurance contract could guarantee a payment of such an amount over such a long period of time. But there will always be a government and it can not go bankrupt. The most simple solution is to provide the insurance in a collective way through the same water board which is responsible for the choice of the safety level and the actual provision of the safety. This also avoids free-rider behaviour.

\subsection{Different situations along a dike ring}

In many cases dike rings have sections along waters with very different characteristics or have defences of a very different nature. For instance, dike ring 14 Central Holland borders the sea, 
the major rivers and canals. Some areas are only protected by one defence - the river dike between Maassluis and Hook of Holland with an open connection to the sea - where other parts of the river dikes are situated behind the Maeslantkering, a storm surge barrier near Rotterdam. The formulation at the end of section 2.1 indicates how to deal with very different situations.

One possibility is that different dike sections defend different compartments within the dike ring. In case there would be only partial flooding of the dike-ring area, the calculation described above should be done separately for each compartment as if they were different dike ring areas.

Second, simulations of possible floodings show that different types of flooding can cause very different effects within the same dike ring. These cases can also be treated within the framework of this model, but that is beyond the scope of this paper (see Eijgenraam (2006), section 3.7).

Here we only look in more detail at the situation in which the defences border different water systems, but in the end every flooding will cause the same amount of damage. ${ }^{7}$ This means that the denominator in equation (2) has always the same value, irrespective the dike section where the flooding starts. In the case of independent causes we can simply split formula (2) in parts:

Middle probability of flooding ${ }_{t}=\frac{\text { yearly costs of a standard investment }}{\text { loss by flooding } \text { fl }_{t}}=$

$$
=\frac{\text { costs standard investment section } A}{\text { loss by flooding }{ }_{t}}+\frac{\text { costs standard investment } \text { section } B}{\text { loss by flooding } t_{t}}
$$

$P_{t}^{\text {middle }}($ total dike ring $)=P_{t}^{\text {middle }}($ section $A)+P_{t}^{\text {middle }}($ section $B)$

The right hand side of equation (3) shows that in the case of independent sections we can simply split the calculation in parts with different parameters or costs. The outcome clearly shows that there is no reason at all why the probability of flooding for section A of a dike ring should be equal to the probability of flooding along another section $\mathrm{B}$. If the sections are along different water systems, like the Meuse and the Waal bordering dike ring 41 Land van Maas en Waal, it is optimal to use different standards for the probability of flooding for both sections.

At present, the law is not clear about the meaning of the legal standard. Must the legal standard be applied to the dike ring as a whole, meaning that the safety level along each different dike section must be much smaller? Or, must the legal standard be applied to each dike section, presently meaning that a dike ring with more than one cause of flooding has a much higher overall probability of flooding than a dike ring with only one cause? It is obvious that the meaning of the law should be clarified and that, according to equation (3), an appropriate value

\footnotetext{
7 There are more complicated cases for which the solution is still unknown, see also conclusion 10.
} 
for separate sections should be preferred. In practice, this will probably result in much higher safety levels for big dike-ring areas.

\section{Outlines of a possible practical strategy}

\subsection{Are the optimal bounds good legal standards?}

How can we use the results described above in the design of a safety policy that can work in practice and how can new legal standards be based on the outcomes of the calculations?

\section{Expected loss or probabilities of flooding?}

The first obvious candidates for use as legal standards are the two bounds of the optimal interval for expected loss. They have the advantage that they are more or less constant in time. But they have the big disadvantage that it is difficult to understand what they really mean in terms of safety. A lower amount of expected loss for one dike ring compared with another does not at all imply a lower probability of flooding. Dike-ring areas differ greatly in size of loss by flooding: Dike ring 14 Central Holland has 3.6 million inhabitants, where e.g. dike ring 42 Ooij en Millingen has 14000 inhabitants. Also, before an assessment on the hydrological situation can be made, a translation would have to be made to probabilities. This task is far from clear and can lead to a lot of uncertainty about the real meaning of the legal standard. A formulation in terms of expected loss does not lead to a clear separation of responsibilities of formulating a goal (legislation) on the one hand and having the task to ensure that the goal will be reached (execution) on the other hand.

So we come to the first conclusions, also based on results from chapter 2:

1. It is to be preferred to formulate legal standards in terms of probabilities of flooding.

2. Probabilities of flooding should refer to each independent dike section separately.

3. It is efficient to base the standards on the own costs and losses by flooding of each dike ring (section) (cost benefit analyses).

4. The more different the safety levels are chosen, the more likely is the desirability of a minimum safety level. This minimum level can by definition not be based on cost benefit analyses, but is a political decision.

5. Optimal probabilities of flooding are not constant in time, but will decline at almost the same rate as the loss by flooding is increasing (economic growth), see section 2.2. Therefore the law should have a procedure for adjusting the legal standards for the probabilities, for instance every ten years. This procedure has also the advantage that for each revision the most recent information can be used.

${ }^{8}$ Many of the remarks in this chapter can be found in CPB (2005). See for derivation of all formulas Eijgenraam (2006). 


\section{Two bounds mean two standards: one for testing and one for designing}

The optimal solution shows that there are two bounds: one for the minimal safety directly before an investment and one with the maximal safety directly after an investment. So, there should also be two legal standards: one, the test standard, for testing whether the actual safety of the dike ring is still above this minimal safety standard and another, the design standard, for indicating the appropriate efficient size of an action.

This is different from the present legal system in the Netherlands in which per dike ring only one standard has been defined. As a consequence, the legal standard (maximum exceedance probability) serves not only as the test standard, as it should, but unfortunately sometimes also as design standard. The ultimate consequence of the present formulation is that the safety system is almost never in accordance with the test standard. Because directly after the safety level would be brought back to the test standard, the actual situation would already have been deteriorated. Using only one standard in a changing environment means continuously investing. In doing so it denies the existence of fixed costs and it prohibits efficient investing. So, the next conclusion is:

6. There should be not one standard, but two standards in the law: one for testing and one for designing.

\subsection{What is a good candidate for the test standard?}

There are several reasons why the calculated value of the lower bound would not be a good value for the test standard. First in theory the very moment the safety level reaches this lower bound, there is immediately investing, so the safety immediately jumps back to the top level. The system is therefore in theory only a moment on the lowest safety level. In practice the law specifies that there will be a test every five years. It is not really feasible to do this more often. When the outcome of the test is negative, a procedure has to be started to overcome the problem. In practice it will take many years before the problem is actually solved. History learns that when real big problems occur (flooding along the Zuiderzee in 1916, flooding along the coast in 1953 or the near flooding along the rivers in 1995), it will take 20 years or more to bring the system to the desired safety level. Therefore the test standard should be chosen in a way that after the test there is still enough time (e.g. 20 years) to solve the problem without reaching safety levels which would be highly unwarranted.

The other reasons for not using the lowest bound have to do with the size of the optimal safety interval. The distance between the two bounds is very sensitive for the ratio between fixed and variable costs. This is intuitively clear: the larger the proportion of the fixed costs, the larger the optimal investment size is and the larger the time span between investments. The split up between the two cost components is in practice not very clear. Besides that, this division can 
greatly differ between different types of action. Since it is not desirable that the legal standard depends heavily on a specific type of action, this is also a good reason not to give the calculated lower safety bound in case of heightening of dikes too much weight in defining the test standard.

More stable is a standard based on the mean optimal expected loss. As formula (1) shows, it is only dependent on average costs. Further, the exceedance of this variable provides indeed a period of about 20 years to repair the problem without the probabilities of flooding becoming too big. For instance, in the actual probability of flooding will exceed the middle optimal probability of flooding around 2060, where the upper bound for the probability would be reached around 2080.

For both reasons the middle probability of flooding (as defined in (2)) is a good starting point for the value of the legal test standard. Therefore we conclude:

7. The middle probability of flooding appears to be a good candidate for the legal test standard:

- It has a good theoretical underpinning;

- On every moment it gives a good idea where the optimal interval is situated;

- It provides enough time for big actions;

- Its value depends only on average costs;

- It is not dependent on a specific type of action;

- Only actual values play a role in the calculation.

\subsection{How to formulate a good design standard?}

Since a chain is as strong as its weakest link, a test standard is uniform for the section of a dike ring along the same water system. However, this uniformity does not apply to a design standard. The reason is that actions to prevent flooding have not always the same effect along a dike ring. An example is the removal of a bottleneck in a riverbed. This has a specific location. Further, such an action can have its own obvious optimal size, which has no relation at all to the size that results out of some general calculation on safety. On top of that, the effect of widening the bottleneck is far from equal along the river. The lowering of the water level is the biggest directly upstream of the location. Further upstream the lowering effect diminishes until it peters out. But directly downstream of the widening, the water level becomes higher. Therefore no general method or value can be given for the most efficient (optimal) size of a specific action on a specific location. The consequence can even be that a combination of separate actions, which are each big on their own, only succeeds in bringing the highest probability of flooding along the dike ring just under the maximum as defined by the test standard.

So, the first conclusion on the design standard is: 
8. The optimal size of each action has to be chosen on its own merits.

However, are there still general guidelines for the evaluation whether an action has an appropriate size, which can be derived from the theoretical solution?

As already has been said, a main driving force behind the optimal size of an action is the relative size of fixed costs compared to total costs. When fixed costs form a big part of total costs it seems logical to choose a big time span before we do this action again, improve it or replace the construction by another one. This is well known in practice. There are civil engineering rules of thumb that it is not a problem to heighten a dike in an open space every 50 years, but that a big construction has to last, for instance, 100 years. It is possible to give these rules of thumb a better theoretical underpinning by calculating the optimal time span for a specific type of investment, e.g. a dike with a grass covering, in a certain area, e.g. along the upstream part of the Rhine. These examples can serve as a guideline in specific situations. So the next recommendation is:

9. Calculate optimal time spans for specific types of action in the different situations (coast, rivers, etc.)

However, it is not at all clear whether separately optimising the size of different types of action on different locations would lead to the overall minimum costs for the whole dike ring. Examples can be constructed for which it is cheaper to treat the whole dike ring as one unit, despite the fact that different parts need different types of actions, e.g. a system of locks in a dike ring with dikes on both sides. At present, the optimal solution of the safety problem in more complicated situations is yet still unknown, which leads to the next conclusion:

10. More mathematical research will be needed to find the optimal solution of the safety problem in more complicated situations, e.g. important correlation between causes of flooding, very different investment costs for locations along the same dike ring or the influence the flooding of one dike ring (or compartment) on the probability of flooding of other dike rings (or compartments). Probably no analytical solution can be derived for these cases, so appropriate numerical procedures have to be developed (see Eijgenraam (2005) appendix A.9 and appendix B or IJzerman, 2005).

The second main driving force in efficient designing is the estimated rate of change of the expected loss. The higher the rate of change, the bigger the size of the action should be, and the smaller the time span till the next action. At present, this driving force is not sufficiently taken into account, because there is only one legal standard which, unfortunately, sometimes also 
serves as design standard. The result is that today the design levels for constructions that have to last for the coming 50 to 100 years, are still the same as the test standards that were considered to be appropriate in the situation 50 years ago. So, where testing is possible without forward looking behaviour, designing is not.

This leads us to the use of scenarios. In principle the Third Policy Paper on the Coast (2000) specifies a good policy in dealing with uncertainty scenarios. The Policy Paper links the ease with which an action can be repeated or corrected, to the type of climate scenario. An action which can easily be repeated, must be robust within the scope of the climate scenario with the smallest rate of deterioration of the water system. Bigger actions, like the heightening of dikes, must be big enough to cope with the changes in the middle climate scenario for a period of 50 years. Actions like reservation or restrictions on the use of areas must be robust for 100 years in the context of the climate scenario with the highest rate of deterioration.

11. Fourth conclusion on the design standard is that the law should provide the possibility for legally enforcing at least a design level as described in the Third Policy Paper on the Coast. Even then the other reason for growth of expected loss would still not be taken into account, namely the rate of growth of the loss by flooding in the dike-ring area. As a proxy the rate of economic growth in the different long-term scenarios of CPB could be used in the same way.

\subsection{Concluding remarks}

In the previous sections 11 conclusions or recommendations have been formulated which sketch the outlines of a safety strategy based on the optimal balance between investment costs and expected loss. To take decisions on values for safety standards actual calculations have to be made. In doing so, further choices have to be made. For instance, is an overall heightening of dikes indeed a good starting point for the calculation of the test standard? It has the advantage that it is applicable to all dike rings. But in particular cases other measures could more appropriate, like removing bottlenecks in riverbeds. However, these types of questions are beyond the scope of this paper.

\section{Appendix}

The formula for the mean expected loss per year can be found in two ways. First as the mean value of the optimal expected yearly loss between two consecutive investments $\left(S^{\text {mean }}\right)$. Since the optimal bounds for the expected loss are constant during such a period (see figure 1.1), the mean is a good indicator for the middle of the interval during this whole period. This central value also emerges in another way, namely as the limit of the loss interval in case the fraction of 
the 'fixed costs' becomes smaller and smaller. ${ }^{9}$ The formula for the centre of the interval of expected loss is (see Eijgenraam, 2006):

$$
S_{i+1}^{\text {mean }} \approx \delta \frac{1}{\theta} \frac{I_{i}(u)}{u}
$$

$\begin{array}{ll}\text { with } & \begin{array}{l}\text { expected loss per year } \\ \delta\end{array} \\ 1 / \theta & \text { discount rate }(\delta>0) \\ & \text { investment size depending on the parameter of the probability } \\ & \text { distribution of flooding } \\ \mathrm{I}(\mathrm{u}) / \mathrm{u} & \text { average investment costs per centimetre } \\ \mathrm{u} & \text { optimal investment size } \\ \mathrm{i} & \text { number of the action }\end{array}$

It turns out that the average expected loss per year depends only on the average costs of protection per centimetre $(\mathrm{I}(\mathrm{u}) / \mathrm{u})$. Average costs are far less dependent on the nature of the preferred action at a specific time and location than the ratio of fixed and variable costs. Where the size of the loss interval (and therefore also the size of $u$ ) is very sensitive for the relative size of fixed and variable costs, obviously the central value of the loss interval is not. If we have different actions with different size effects on the costs of these actions but with roughly the same unit costs for an optimal investment size, then the mean optimal expected loss will also be roughly the same.

To find the middle of the probability interval $\left(\mathrm{P}^{\text {middle }}(\mathrm{t})\right)$ we apply the definition of expected loss to the outcome of (1):

$$
P_{t}^{\text {middle }}=\frac{S_{i+1}^{\text {mean }}}{V_{t}}
$$

$\begin{array}{lll}\text { with } & \mathrm{P} & \text { probability of flooding per year } \\ & \mathrm{V} & \text { (potential) loss by flooding }\end{array}$

\footnotetext{
${ }^{9}$ No 'fixed costs' means that neither the size nor the timing of an action has any influence on the unit costs of that action.

${ }^{10}$ See for the formula of $u$ in case $u$ can freely be chosen Eijgenraam (2005) or Eijgenraam (2006). Mostly the average costs do not differ that much for values of $u$ not too far away from the optimal one.
} 


\section{References}

Centraal Planbureau, 2005, Urgentie van acties omtrent veiligheid tegen overstromen, CPB Notitie, 30 juni 2005 (in Dutch).

Dantzig, D. van, 1956, Economic decision problems for flood prevention; Econometrica Vol. 24, p 276-287.

Eijgenraam, C.J.J., 2005, Veiligheid tegen overstromen, Kosten-batenanalyse voor Ruimte voor de Rivier, deel 1; CPB Document 82, april 2005 (in Dutch).

Eijgenraam, C.J.J., 2006, Optimal safety standards for dike-ring areas, CPB Discussion paper 62, March 2006.

Ministerie van Verkeer en Waterstaat, 2000, 3e Kustnota Traditie, Trends en Toekomst, december 2000 (in Dutch).

IJzerman, J.F., 2005, Het modelleren en optimaliseren van dijkverhogingen, HKV, mei 2005. 